\title{
15 GEOINT and the post-secret world
}

\author{
Who guards the guards?
}

\author{
Robert Cardillo
}

We are fast approaching the time in which technology will enable a continuous sensing of all of the world's activity - 24 hours a day, seven days a week, 365 days a year. Such holistic collection will facilitate a detailed model of the planet and all that is happening on it. There are many benefits of such a model, including natural disaster preparedness and response, enhanced measurements of the environment and real-time detection of nefarious actors. However, such a world will demand a rethinking of privacy itself, requiring us to find the optimum balance between the benefits of this technology, their implications for our privacy and the potential for misuse. Exploring that balance is the overriding purpose of this chapter. While a definitive answer will not be delineated, I will present the key questions which will guide our thinking.

"Quis custodiet ipsos custodes?" literally means "Who will guard the guards themselves?" For our purposes, a variant of that translation will be more constructive: "Who watches the watchers?" In the past, the watchers were governments - for good and for bad - and the original driver for remote sensing technologies was national security. When the Iron Curtain was drawn across Europe, the US Government and its allies needed to access the denied territory of the Soviet Union in order to identify the magnitude of the military threat. Wrapped in layers and layers of secrecy, such access was first provided by the U-2 aircraft's intelligence, surveillance and reconnaissance mission (Lockheed Martin n.d.).

Over the next five years, the U2's innovation provided President Eisenhower with unprecedented insight into denied territory and enhanced understanding of a critical threat and over 100 flights collecting thousands of images. However on May 1, 1960, a Soviet SA-2 surface-to-air missile shot down a U2 aircraft, not only removing our ability to surveil our adversaries but also revealing our tactics, techniques and procedures (History 2018). We were blind and that blindness created doubt, uncertainty and risk.

That blindness lasted a little more than 100 days; on August 18, 1960, the thentop secret CORONA satellite programme took its first image from space, a grainy picture of a strategic Soviet airfield. The United States again had access to denied 
territory, providing insight and an ultimate advantage over our adversaries. In 1995, Vice President Gore stated the CORONA satellites,

recorded much more than the landscape of the Cold War. In the process of acquiring this priceless data, we recorded for future generations the environmental history of the Earth at least a decade before any country on this Earth launched any Earth resource satellites.

(CIA 2015)

In order to collect such critical imagery intelligence, the creators of the CORONA satellite had to overcome many obstacles:

- $\quad$ determine a way to expose film via a shutter and lens system travelling at 23,500 mph

- $\quad$ solve for the necessary speed of the film feed system

- contain the exposed film

- $\quad$ eject the capsule of film

- $\quad$ send the capsule of film back through the atmosphere

- deploy a parachute at altitude

- modify an Air Force transport with a trapeze to catch the capsule as it floated down over the Pacific

All to say, it took innovative science and enormous investment amidst extraordinary secrecy to create the ability to document activity on earth from space.

Over the course of the next 50 years, there was a halting and gradual shift of that capability from the government to the commercial sector. This shift has recently accelerated, resulting in a sharp increase in commercial capabilities in space. Beyond the visible images captured in the electro-optical spectrum, there are now commercial radar satellites as well as those that capture radio frequencies and infrared.

With this rapid and steep commercial growth, some argue that we are entering into an era of geospatial "singularity". This scenario

coined the GEOINT Singularity, is a future where real-time Earth observations with analytics are available globally to the average citizen on the ground providing a tremendous wealth of information, insight, and intelligence.

(Koller 2019)

Dr Josef Koller, a global security and space science programme expert, believes, "technology trends are accelerating and there are indications that a sixth wave of innovation is coming". Dr Koller reminds us of the five initial economic cycles defined as the industrial revolution; the age of steam and railways; the age of steel and electricity; the age of oil, cars and mass production and the age of information and communication (Koller 2019).

Each wave lasted from 40 to 60 years and consisted of alternating periods between high sector growth and periods of slow growth. The sixth cycle is 
postulated by some as an increase in resource efficiency. A new wave would be heralded by massive changes in the market, societal institutions and technology that all reinforce each other, centered around connected intelligence with new devices, new applications, new business models and new services. Space-based commercial remote sensing that create massive datasets, joined by $[\mathrm{AI}]$ for analysis and product development will be just one aspect of the innovation wave.

(Koller 2019)

With this increase in innovation and technological advances, the potential for transparency escalates exponentially, an attribute I find pertinent to our success as a liberal democracy in this technological age.

One of the many benefits of embracing satellite imagery and artificial intelligence (AI) into our daily life is the ability to predict natural disasters. Since 2000, spaceborne satellites and sensors have helped experts "quantify geophysical phenomena associated with the movements of the earth's surface (earthquakes, mass movements), water (floods, tsunamis, storms), and fire (wildfires)" (Gillespie et al. 2007). This technology plays an important role in assessing disasters before and after they occur (Gillespie et al. 2007). Specialists are turning to "geodetic methods - the math-based study of changes in the Earth's shape - that use satellites and other instruments to complement data gathered by seismometers" to better predict the earth's "movements and landslides" (Joshi 2019; Lewis 2019). A University of Iowa student demonstrated this by processing:

radar imagery, or interferograms, from a 6.9 magnitude quake that struck Indonesia in August 2018. She then used this imagery to produce a model of the earthquake and where it was located. The [United States Geological Survey] used this model directly to update its predictions of ground shaking and earthquake impact that were incorporated into its disaster-response systems.

(Lewis 2019)

These efforts directly improved earthquake estimates and solidified the importance of satellite imagery in predicting future natural disasters (Lewis 2019).

Furthermore, during Hurricane Harvey, The National Aeronautics and Space Administration (NASA) collaborated with the mapping and data visualization team at Development Seed to track Harvey's rainfall, cloud heights and cloud top temperatures (Joshi 2019; Dempsey 2017). This technology allowed experts to track the hurricane's progress every hour, as opposed to every six hours, which was the standard tracking capability (Joshi 2019).

$\mathrm{AI}$ is also being used to protect and improve the environment in the form of monitoring endangered species, tracking diseases and optimizing crops. For example, WildTrack uses a "computer vision solution called Footprint Identification Technology to monitor endangered species non-invasively. The tool analyses images of footprints of cheetahs, rhinos, and other endangered species to identify them, track them, and determine what threatens them" (DeNisco Rayome 2019). AI can "also track mosquito populations to anticipate or prevent the spread of 


\section{Robert Cardillo}

disease, as well as weather changes, to warn populations about upcoming storms" (DeNisco Rayome 2019).

Epidemiology, the study of disease propagation, has long relied on maps, starting with John Snow's iconic maps of the London cholera outbreak in 1854. These maps may have been the beginning of geographic analysis as we know it - overlaying seemingly disparate elements on a map to reveal previously unseen patterns.

(OECD 2020)

Thanks to Geospatial technologies like AI, the spread of COVID-19 is being mapped in real time.

Before the world was even aware of the threat posed by the coronavirus (COVID-19), artificial intelligence (AI) systems had detected the outbreak of an unknown type of pneumonia in the People's Republic of China (hereafter "China"). As the outbreak has now become a global pandemic, AI tools and technologies can be employed to support efforts of policy makers, the medical community, and society at large to manage every stage of the crisis and its aftermath: detection, prevention, response, recovery and to accelerate research.

(OECD 2020)

AI is a contributing factor as governments attempt to limit contagion. Countries are using AI methods to surveil their population and conduct contact tracing, among other things.

A number of countries are using population surveillance to monitor COVID19 cases (for example, in Korea algorithms use geolocation data, surveillance-camera footage and credit card records to trace coronavirus patients). China assigns a risk level (colour code - red, yellow or green) to each person indicating contagion risk using cell phone software. While machine learning models use travel, payment, and communications data to predict the location of the next outbreak and inform border checks, search engines and social media are also helping to track the disease in real-time.

(OECD 2020)

Even before the COVID-19 outbreak, governments were adopting closed-circuit television cameras combined with AI in cities across the globe. Some cities may even utilize private companies to gather publicly available photographs and data from the internet (Goldenfein 2020). One service in particular, Clearview AI, is "like a reverse image search for faces" (Goldenfein 2020). As the global social networks expand, the raw material for such an application grows every day:

You take a picture of a person, upload it and get to see public photos of that person, along with links to where those photos appeared. The system - 
whose backbone is a database of more than three billion images that Clearview claims to have scraped from Facebook, YouTube, Venmo and millions of other websites - goes far beyond anything ever constructed by the United States government or Silicon Valley giants.

(Hill 2020)

With this increase in imagery and data collection, we will be able to holistically cross-connect data streams from human activity to physical reality; ultimately answering the questions, "Where are the people?" "Why are the people there?" and "Where are they going to be tomorrow?" Having the ability to answer these questions could contribute to the prevention of mass shootings, police brutality or maintaining peace during protests or daily life. For instance, law enforcement officers, including local police in Florida, the Federal Bureau of Investigation (FBI) and the Department of Homeland Security, have used Clearview AI to assist with cases involving shoplifting, identity theft, credit card fraud, murder and child sexual exploitation cases (Hill 2020).

However, the collection of one's daily actions, movements or publicly available information could be used with malice. If mishandled, employers, government leaders or adversaries (personal or political/non state actors) could use this information as leverage against those with opposing viewpoints. In this instance, we risk being manipulated for another person's gain. Due to this fear, it is likely most Americans would feel their freedoms were violated if Congress attempted to mandate that every adult carry a tracking device to reveal their location 24 hours a day (Thompson and Warzel 2019a). Yet, in the decade since Apple created its App Store and General Motors created OnStar, the majority of Americans have, application by application, consented to such a system run by private companies, even though the corporations that control their data are far less accountable than the government would be (Thompson and Warzel 2019a). In an exposé on the topic, The New York Times states:

Americans have grown eerily accustomed to being tracked throughout their digital lives. But it's far from their fault. It's a result of a system in which data surveillance practices are hidden from consumers and in which much of the collection of information is done without the full knowledge of the device holders.

(Thompson and Warzel 2019b)

Many Americans simply risk embarrassment or inconvenience should their location data be exposed, but for victims of abuse, the risks are substantial as this information could be used by their abuser for further attacks (Thompson and Warzel 2019a). The New York Times also reminded their readers that not all people want their locational data shared:

Who can say what practices or relationships any given individual might want to keep private, to withhold from friends, family, employers or the 
government? We found hundreds of pings in mosques and churches, abortion clinics, queer spaces and other sensitive areas.

(Thompson and Warzel 2019a)

With the innovations surrounding AI and geospatial technologies, the concept of privacy has evolved. Should our liberal democracy maintain transparency in regards to this technology, the concept of privacy will continue to morph, for good or for bad. For example, in May 2019, the city of San Francisco became the first city in the United States to ban the use of facial recognition software by police and other city agencies (Fowler and Breedlove 2019). While this technology could provide assistance in fighting crime, it could also be used for evil or unjust reasons. For example, if a child was kidnapped from a city park prior to this ban, San Francisco would be able to use a combination of CCTVs and facial recognition software to identify the kidnapper, track his or her location, retrieve the missing child and return them to his or her parents. A city employee, however, could misuse the technology at his or her disposal to track a former spouse during a divorce settlement. Perhaps this employee's former spouse is claiming to be unable to afford child support or alimony, claims to be eating at food shelters and struggling to make ends meet. However, with CCTVs and facial recognition, the city employee is able to prove that the former spouse is frequenting lavish stores and five star restaurants. In this instance, the technology that could be used for good becomes an abuse of power and a tool to invade someone's privacy. Furthermore, "facial recognition algorithms have long been criticized for poor performance in identifying non-white faces" (Hatmaker 2020). This issue contributes to San Francisco's decision to ban such technology: “[t]he propensity for facial recognition technology to endanger civil rights and civil liberties substantially outweighs its purported benefits" (Fowler and Breedlove 2019).

If not properly regulated with transparency, this technology could also be used to threaten our national security. For example, in the same exposé referenced previously, the New York Times used locational data to track one of president Trump's secret service agents, and by association, likely president Trump himself (Thompson and Warzel 2019b). The potential this information could have against our national security is obviously immense and there's little stopping an adversary from utilizing this information to our detriment. For instance, according to former National Security Agency director General Michael Hayden, "the U.S. government 'kill[s] people based on metadata"'. If this is a practice we take part in, it could also be adapted by adversaries through readily available, public information.

As the expansion and growth of such surveillance is inevitable and incessant, we must calculate a means to deal with such a reality. If approached with caution, this will benefit our society exponentially. In his 1998 book, The Transparent Society, David Brin shares similar sentiments:

This is a tale of two cities. Cities of the near future, say ten or twenty years from now. Barring something unforeseen, you are apt to be living in one these two places. Your only choice is which one. 
Consider city number one. In this place, all the myriad cameras report their urban scenes straight to Police Central, where security officers use sophisticated image processors to scan for infractions against public order - or perhaps an established way of thought. Citizens walk the streets aware that any word or deed may be noted by agents of some mysterious bureau.

At first sight, things seem quite similar in city number two. Again, ubiquitous cameras perch on every vantage point. Only here we soon find a crucial difference. These devices do not report to the secret police. Rather, each and every citizen of this metropolis can use his or her wristwatch television to call up images from any camera in town.

In city number two, such micro-cameras are banned from some indoor places . . . but not from police headquarters! There any citizen may tune in on bookings, arraignments, and especially the camera control room itself, sure that the agents on duty look out for violent crime, and only crime.

Both futures may seem undesirable. But can there be any doubt which city we'd rather live in, if these two make up our only choice?

(Brin 1999)

Brin's challenging question to choose from extremes is useful in the grey area that is real life. But given the relentless nature of commercial surveillance, Brin gives us a reference point from which to anchor the necessary details of our policy debate. The abundance of publicly available information is changing the definition of "private". In an article for the Brookings Institute, Cameron Kerry states:

To most people, 'personal information' means information like social security numbers, account numbers, and other information that is unique to them. U.S. privacy laws reflect this conception by aiming at 'personally identifiable information,' but data scientists have repeatedly demonstrated that this focus can be too narrow. The aggregation and correlation of data from various sources make it increasingly possible to link supposedly anonymous information to specific individuals and to infer characteristics and information about them. The result is that today, a widening range of data has the potential to be personal information, i.e. to identify us uniquely.

(Kerry 2018)

The European Union agrees with this sentiment: Brought to fruition in May 2018, the General Data Protection Regulation (GDPR) significantly altered the privacy laws throughout the European Union. The GDPR is focused largely on protecting personal data, to include "racial or ethnic origin, political opinions, religious beliefs, membership of trade unions, genetic and biometric data, health information and data around a person's sex life or orientation" (Burgess 2020). At the core of the GDPR legislation, there are seven principles that "don't act as hard rules, but instead as an overarching framework that is designed to layout the broad purposes 
of GDPR" (Burgess 2020). The seven principles are: "lawfulness, fairness and transparency; purpose limitation; data minimisation; accuracy; storage limitation; integrity and confidentiality (security); and accountability" (Burgess 2020). However, certain provisions could override the GDPR legislation, including national security, defence and public security (European Parliament and Council of European Union 2016).

Currently, US privacy laws focus on threats against individual's rights, but those protections are anachronistic in the face of AI, geospatial technologies and mobile technologies, which not only use group data but also are dependent on it. We must determine who controls our data, who can access it, why it can be accessed and with what oversight. Finally, we need to firmly establish what role if any - the derived data would play in our legal framework. We ultimately need to answer the question, "How might our society adapt, innovate and evolve to harness the power of geospatial data and technology while mitigating its ethical challenges"?

As we seek to address that question, we must remember these are unchartered waters and uninformed, impetuous actions could have deleterious effects. It is essential this unprecedented situation be addressed with deliberate and well thought out actions, as well as the flexibility and ability to modify rules and regulations as we better understand the ramifications and consequences of our initial decisions. Currently, the most applicable legal notion along these lines may be the Fourth Amendment Equilibrium Adjustment, which:

posits that the Supreme Court adjusts the scope of protection in response to new facts in order to restore the status quo level of protection. When changing technology or social practice expands government power, the Supreme Court tightens Fourth Amendment protection; when it threatens government power, the Supreme Court loosens constitutional protection.

(Kerr 2011)

While this is a far cry from what liberal democracies must create in order to adequately protect individuals' privacy outside the court of law, the premise may serve as an appropriate baseline and reminder for a fluid, constantly changing, law. I would observe that until we can agree on data privacy norms, it will be hard to create lasting rules around transparency. Suffice it to say, the stakes are enormous. In fact, one could see this discussion and debate as existential - at least as it pertains to human freedoms.

Just as search engines like Google led the way for indexing and categorizing the knowledge deposited by humans into the online world for mankind's benefit, a globally persistent sensing architecture could lead the way to finding information, intelligence and understanding of the physical world in real time to benefit all life on earth. Like others, I have used the analogy of the rising tide of data that can overwhelm us by bringing us more data and less information, ultimately reducing our shared awareness. That tide is cresting in a way that puts us now on the curling edge of the wave. Computer vision, machine-learning and AI offer the chance for 
us to propel into a world of radical transparency. Each advancement in technology will build upon and interface with their predecessors. This accumulation is essential from a commercial utility perspective. And it will redound to the public sphere if and when such transparency is misused - especially by the government.

Our transparent society is here to stay, no matter how hard one tries to eliminate their digital presence. There is no putting this technological genie back in the bottle. I submit that transparency favours justice - and that evil lurks in the dark. If you think of this transparency as light - as I do - it shines both ways. I believe transparency is good for liberal, democratic societies. As Supreme Court Justice Louis Brandeis observed, "Sunlight is said to be the best of disinfectants" (Brandeis 1914, chap. 5).

I further believe the bedrock of civil discourse is trust; not so we agree on every issue, rather so we appreciate the other perspective and empathize with differing views. Properly thought through, an era of radical transparency can lead to a more humane world. However, achieving such a world means striking a balance between access and control, between openness and privacy, between good and evil.

Thus, we should be considering our country's core strengths - entrepreneurial spirit, risk capital, market competition and respect for the individual and their rights - as we rethink what the notion of privacy should mean today. If we anticipate many of the ways that the abundance of data might be misused, we can establish rules, regulations and governing authorities to encourage the best uses while thwarting bad actors. After all, as we've learned during the ongoing COVID-19 pandemic, modifying prior constructs of privacy has enabled countries to conduct holistic contact tracing, limiting the spread of a deadly disease. If approached with thought and caution, this technology has the potential to make transparency a force for good and change the world for the better.

\section{References}

Brandeis, Louis D. 1914. Other People's Money and How the Bankers Use It. New York: Frederick A. Stokes Company.

Brin, David. 1999. The Transparent Society: Will Technology Force Us to Choose between Privacy And Freedom? 1st edition. Reading, MA: Basic Books.

Burgess, Matt. 2020. "What Is GDPR? The Summary Guide to GDPR Compliance in the UK”. Wired UK, March 24. www.wired.co.uk/article/what-is-gdpr-uk-eu-legislationcompliance-summary-fines-2018.

CIA. 2015. "CORONA: Declassified - Central Intelligence Agency”. CIA.Gov. 2015. Accessed December 16, 2020. https://web.archive.org/web/20201101124231/www. cia.gov/news-information/featured-story-archive/2015-featured-story-archive/coronadeclassified.html.

Dempsey, Caitlin. 2017. "Tracking Hurricane Harvey with Satellites”. Geography Realm (blog). August 25. www.geographyrealm.com/tracking-hurricane-harvey-satellites/.

DeNisco Rayome, Alison. 2019. "How AI Could Save the Environment". TechRepublic (blog). April 19. www.techrepublic.com/article/how-ai-could-save-the-environment/.

European Parliament and Council of European Union. 2016. “Art. 23 GDPR-Restrictions". Accessed February 26, 2018. https://gdpr-info.eu/art-23-gdpr/. 
Fowler, Patrick, and Haley Breedlove. 2019. "Facing the Issue: San Francisco Bans City Use of Facial Recognition Technology". JD Supra (blog). July 15. www.jdsupra.com/ legalnews/facing-the-issue-san-francisco-bans-35144/.

Gillespie, Thomas W., Jasmine Chu, Elizabeth Frankenberg, and Duncan Thomas. 2007. "Assessment and Prediction of Natural Hazards from Satellite Imagery". Progress in Physical Geography 31 (5): 459-70. https://doi.org/10.1177/0309133307083296.

Goldenfein, Jake. 2020. "Australian Police Are Using the Clearview AI Facial Recognition System with No Accountability". The Conversation, March 4. http://theconversation. com/australian-police-are-using-the-clearview-ai-facial-recognition-system-with-noaccountability-132667.

Hatmaker, Taylor. 2020. "AI Researchers Condemn Predictive Crime Software, Citing Racial Bias and Flawed Methods | TechCrunch". TechCrunch (blog). June 24. https:// techcrunch.com/2020/06/23/ai-crime-prediction-open-letter-springer/.

Hill, Kashmir. 2020. "The Secretive Company That Might End Privacy as We Know It". The New York Times, January 18, sec. Technology. www.nytimes.com/2020/01/18/technology/clearview-privacy-facial-recognition.html.

History. 2018. "U-2 Spy Incident”. History (blog). August 21. www.history.com/topics/ cold-war/u2-spy-incident.

Joshi, Naveen. 2019. "How AI Can and Will Predict Disasters". Forbes, March 15. www. forbes.com/sites/cognitiveworld/2019/03/15/how-ai-can-and-will-predict-disasters/.

Kerr, Orin S. 2011. “An Equilibrium-Adjustment Theory of the Fourth Amendment". Harvard Law Review, December 20. https://harvardlawreview.org/2011/12/an-equilibriumadjustment-theory-of-the-fourth-amendment/.

Kerry. 2018. "Why Protecting Privacy Is a Losing Game Today - and How to Change the Game". Brookings (blog). July 12. www.brookings.edu/research/why-protectingprivacy-is-a-losing-game-today-and-how-to-change-the-game/.

Koller, Josef S. 2019. "The Future of Ubiquitous, Realtime Intelligence: A GEOINT Singularity". In 35th Space Symposium, Technical Track, Colorado Springs, Colorado, United States of America. www.spacesymposium.org/wp-content/uploads/2019/09/ Paper-Koller-Josef-A-Future-of-Ubiquitous-Real-Time-Intelligence.pdf.

Lewis, Richard. 2019. "Satellite Observations Improve Earthquake Monitoring, Response". ScienceDaily (blog). June 14. www.sciencedaily.com/releases/2019/06/190614125848. htm.

Lockheed Martin. n.d. "U-2 Dragon Lady". Lockheed Martin. Accessed December 16, 2020. www.lockheedmartin.com/en-us/products/u2-dragon-lady.html.

OECD. 2020. "Using Artificial Intelligence to Help Combat COVID-19". OECD.org. April 23. www.oecd.org/coronavirus/policy-responses/using-artificial-intelligence-tohelp-combat-covid-19-ae4c5c21/.

Thompson, Stuart A., and Charlie Warzel. 2019a. "Twelve Million Phones, One Dataset, Zero Privacy". The New York Times, December 19. www.nytimes.com/interactive/ 2019/12/19/opinion/location-tracking-cell-phone.html.

_. 2019b. "How to Track President Trump". The New York Times, December 20. www.nytimes.com/interactive/2019/12/20/opinion/location-data-national-security.html. 